\title{
IMPLEMENTASI ALGORITHM CNN DAN SLTM UNTUK TRANSLATOR THINGS
}

\author{
Al Abdul Rohim ${ }^{1}$, Taufiq Nashrullah ${ }^{2}$, Anggit Dwi Hartanto ${ }^{3}$, Hartatik ${ }^{4}$ \\ 1,2,3 Fakultas Ilmu Komputer Universitas Amikom Yogyakarta \\ 1'Abdul.rohim@stundets.amikom.ac.id, ${ }^{2}$ Taufiq.Nashrullah@students.amikom.ac.id, \\ 33Anggit@amikom.ac.id,, ${ }^{4}$ hartatik@amikom.ac.id
}

\begin{abstract}
Translator Things is a technology that allows users to find out the names of objects in a variety of foreign languages, by using a cellphone / laptop camera, Translator Things is very useful if we are abroad and we can find out the name of the object that our country is visiting. For the System we use CNN and LSTM as CNN's algorithm to identify objects on the camera, and LSTM to translate text on the identification of these objects The results of this discussion will identify objects that will be identified through text.
\end{abstract}

Keywords: Translator Things, CNN, LSTM, Translating.

\section{PENDAHULUAN}

Bahasa merupakan hal yang penting untuk dapat berkomunikasi, namun tidak semua orang menggunakan bahasa yang sama di setiap negara. Teknologi ini ditujukan untuk orang-orang yang suka traveling keluar negeri dan orang-orang yang mau belajar bahasa inggris, dalam kehidupan keseharian kita diluar negeri harus mengetahui barang-barang yang ada dikehidupan kita yang kita perlukan untuk menanyakan kepada masyarakat local, dengan menggunakan software ini membuat kita yang ingin keluar negeri mudah mengenali barang-barang disekitar. Ada kelemahan pada project sebelumnya menggunakan metode pemrosesan gambar secara manual mendeteksi pada suatu gambar. Setelah melakukan OCR pada daerah yang terdeteksi harus jelas, jika gambarnya tidak terlihat bagus akan tidak jelas juga pada penerjemahaannya.

\section{METODE}

Metode Penelitian dipergunakan untuk menyelesaikan masalah pada penelitian ini, kemudian akan membangun sebuah Convolutional Neural Network (CNN) dengan data set yang kita gunakan untuk melatih, sehingga dapat mendeteksi barang-barang yang ada disekitar kita, data set terbagi menjadi data latih dan data uji, disini kita menggunakan contoh objek gambar kucing dan anjing untuk data latih terdapat 8 ribu gambar untuk masing-masih kategori. Dalam Long Short Term Memory (LSTM) Model tersebut digunakan untuk melatih data yang sudah dalam bentuk vector, setelah pelatihan selesai dilakukan uji coba pengenalan gambar pada teks.

\section{A. Convulational Neural Network(CNN)}

Pada Convulational Neural Network (CNN) merupakan pengembangan dari Multi Layer Perceptron (MLP) yang didesain untuk mengelola dua dimensi.CNN termasuk dalam jenis Deep Neural Network karena kedalaman jaringan yang tinggi dan banyak diaplikasikan pada data citra.

CNN memiliki kesamaan dengan MLP, tetapi CNN dipresentasikan dalam bentuk dua dimensi, pada CNN operasi linear menggunakan operasi konvolusi, sedangkan bobot berbentuk empat dimensi yang merupakan kumpulan kernel konvolusi seperti pada gambar.1. Dimensi bobot pada CNN adalah:

neuron input $\mathrm{x}$ neuron output $\mathrm{x}$ tinggi $\mathrm{x}$ lebar

Karena sifat proses konvolusi maka CNN hanya dapat digunakan pada data yang mempunyai struktur dua dimensi seperti citra dan suara.[4] 


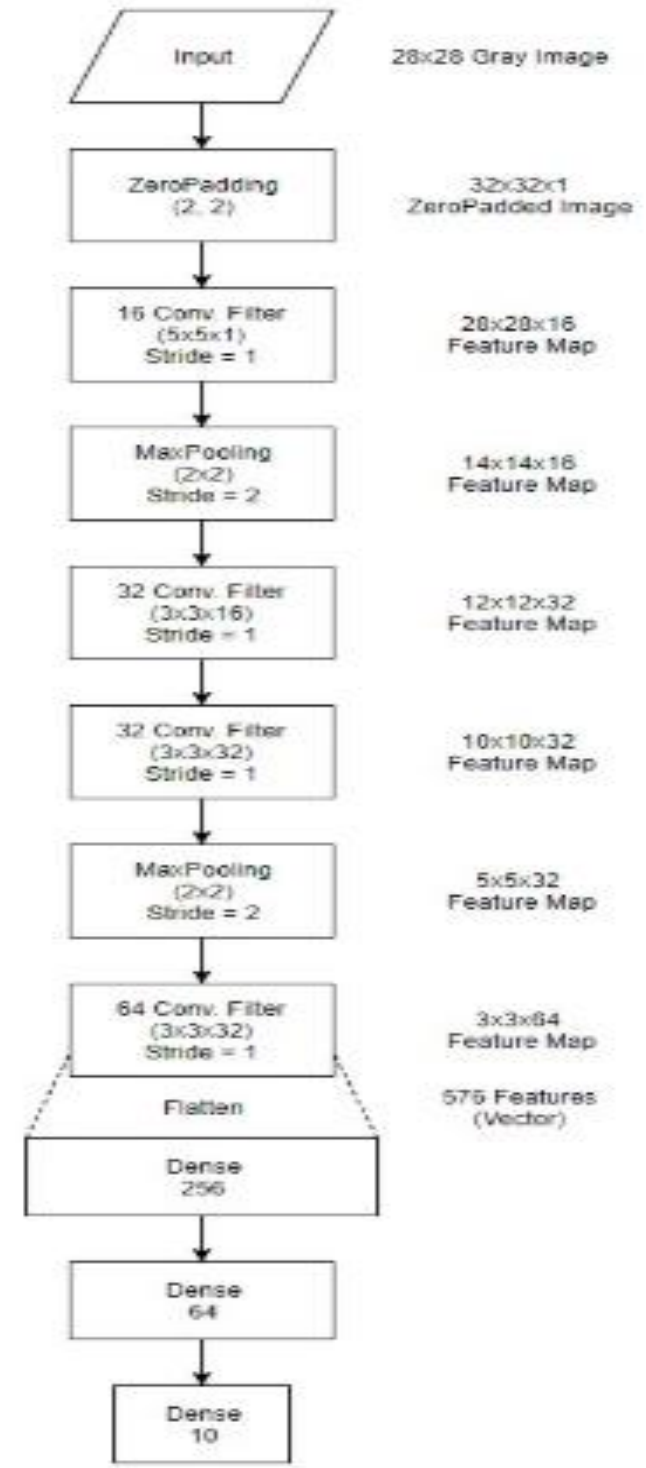

layer $\mathrm{m}-\mathrm{I}$

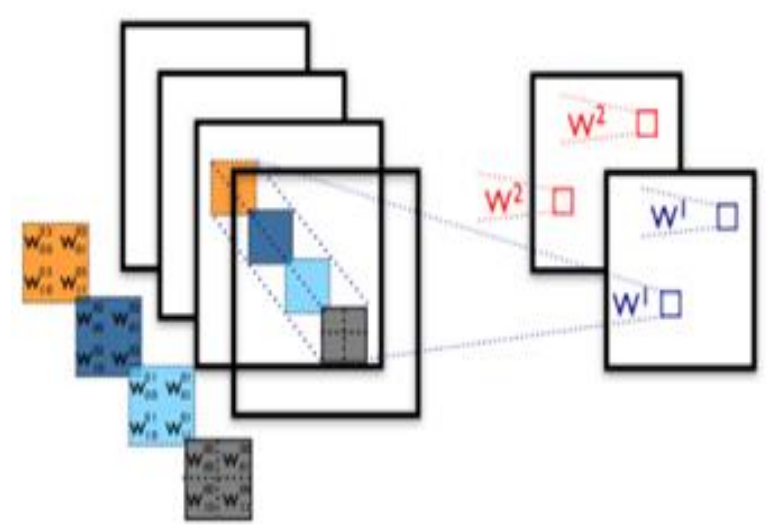

Gambar 1. Struktur dua dimensi

terdapat data latih sebanyak delapam ribu gambar untuk masing-masing kategori sedangkan untuk data uji masing-masing kategori memiliki dua ribu gambar. Ada empat tahapan untuk membangun model CNN yang Step Pertama Convulution, Step Kedua Polling, Step Ketiga Flattening, Step Keempat Full Connection.

\section{B. Long Short Term Memory(LSTM)}

Sedangkan Metode Long Short Term Memory (LSTM) dimulai dari mempersiapkan dataset yang digunakan sebagai data latih, lalu data, Lalu data tersebut diolah agar menjadi data yang memiliki tahapan mulai dari mengenalkan gambar menjadi teks, layer diubah menjadi vector dalam proses vektorisasi, model tersebut digunakan untuk melatih data yang sudah dalam bentuk vector, pada tahap terakhir evaluasi terhadap keakuratan model yang sudah dibuat.

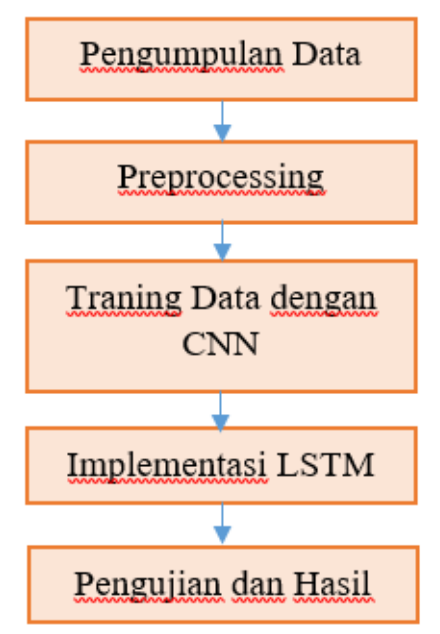

Gambar 2. Alur Penelitian

\section{Rumus Matematika}

Untuk menghitung dimensi peta fitur, kita dapat menggunakan rumus seperti di bawah ini: Output $=\frac{W-N+2 P}{S}+1$

$\mathrm{W}=$ Panjang $/$ Tinggi Input

$\mathrm{N}=$ Panjang / Tinggi Filter

$\mathrm{P}=$ Zero Padding

$\mathrm{S}=$ Melangkah

\section{HASIL DAN PEMBAHASAN}

\section{Pembahasan Data I}

\section{Ekstraksi Layer}

Pada proses ekstraksi, mencoba dengan ukuran filter $5 \times 5$ dan $3 \times 3$, namun digunakan $2 x$ proses downsampling.

Dan dapat diingat bahwa semakin kecil stride maka semakin banyak gambar yang dapat di extract 
inputs $=\operatorname{Input}($ shape $=(28,28,1))$

conv_layer $=$ ZeroPadding2D $($ padding $=(2,2))$ (inputs)

conv_layer $=$ Conv $2 D(16,(5,5)$, strides $=(1,1)$, activation='relu') $($ conv_layer $)$

conv_layer $=$ MaxPooling2D $((2,2))($ conv_layer $)$

conv_layer $=\operatorname{Conv} 2 \mathrm{D}(32,(3,3)$, strides $=(1,1)$, activation='relu') $($ conv_layer $)$

conv_layer $=\operatorname{Conv} 2 \mathrm{D}(32,(3,3)$, strides $=(1,1)$, activation='relu' $)($ conv_layer $)$

conv_layer $=$ MaxPooling2D $((2,2))($ conv_layer $)$

conv_layer $=\operatorname{Conv} 2 \mathrm{D}(64,(3,3)$, strides $=(1,1)$, activation='relu' $)($ conv_layer $)$
Teknologi Informasi dan Ilmu Komputer (JTIIK), Indonesia, 2019

[2]. samuelsena "pengenalan-deep-learning-part-7convolutional-neural-network-cnn-b003b477dc94" in medium.com, Indonesia, 2017

[3]. Aditya yanuar.r "klasifikasi-gambar-sederhanamenggunakan-convolutional-neural-network" machinelearning.mipa.ugm.ac.id, Indonesia, 2018

[4]. I Wayan Suartika E. P, Arya Yudhi Wijaya, dan Rully Soelaiman "Klasifikasi Citra Menggunakan Convolutional Neural Network (Cnn) pada Caltech 101" in Jurnal TEKNIK ITS, Indonesia, 2016

\section{Comparing}

Dengan menguji menggunakan TensorBoard, kita dapat membandingkan perfoma kedua model.

Grafik warna biru adalah grafik dari model yang menggunakan conv, layer yang lebih banyak, performa pada model pertama lebih unggul dari pada model kedua,

Dengan Hasil Training dan Validation Loss yang didapat, sebenarnya dapat di kembangkan lagi.

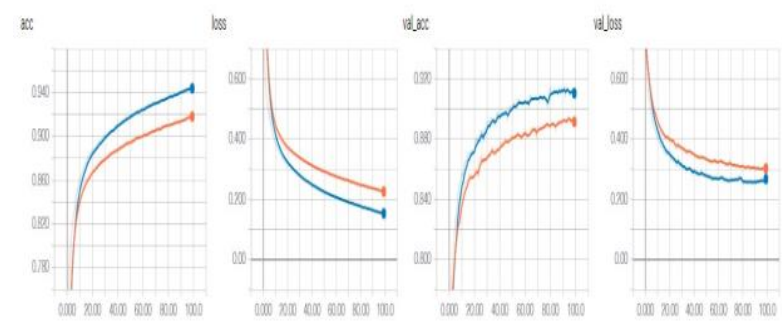

\section{TensorBoard}

Dengan menggunakan tensorboard untuk melakukan visualisasi pada saat training, kita dapat lihat presentase pada accuracy yang didapat untuk validation.

callbacks $=$ TensorBoard $\left(\log _{-}\right.$dir $=$'./Graph' $)$

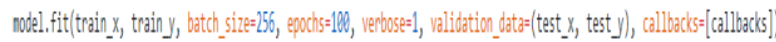

\section{KESIMPULAN}

Jadi berdasarkan ujiset yang telah dicoba menggunakan kurang lebih 8 ribu data dengan inputan gambar kucing dan anjing, kita dapat hasil presentase untuk membedakan kedua gambar tersebut, sehingga kita bisa menginputkan gambar melalu kamera dan dapat membedakan antara kucing dan anjing.

\section{DAFTAR PUSTAKA}

[1]. Kasyfi Ivanedra and Metty Mustikasari "Implementasi Metode Recurrent Neural Network Pada Text Summarization Dengan Teknik Abstraktif" in Jurnal 